\title{
Entre Visagens e Casaróes: Considerações sobre formas de vulnerabilidade a partir dos vigilantes do Centro Histórico de São Luís
}

GABRIELA LAGES GONÇALVES

\section{Apresentando os perigos}

Dona Nazaré me alertava, como em um 'tutorial', sobre o que eu deveria fazer caso eu visse ou sentisse um vulto durante a minha pesquisa de campo: "Vá até um banheiro com espelho e diga 'Senhor me cobre com teu sangue, me faz invisível aos olhos do maligno', entendeu? Pois, Eu, Nazaré, faria isso. Aqui ó, [apontava para a rua repleta de casarões], esses casarões têm um negócio de pomba-gira, essas coisas, isso é só coisa do capeta!", exclamou enquanto eu e D30 - um dos vigilantes do Prédio de História da Universidade Estadual do Maranhão, localizado no Centro Histórico de São Luís - gargalhávamos de suas instruções.

Nesse dia, D30 acabou por ocasionar uma roda de conversa com seus amigos da zeladoria. O tema era o mesmo de sempre: vultos, vozes, passos, barulhos, objetos que se movem, entre outras 'coisas estranhas'. Ao se aproximar, Dona Nazaré descobriu que o assunto era sobre um espírito que mudava vassouras de lugar e assobiava. Ela nos contou algumas histórias de seus colegas de trabalho em outro prédio da Universidade, onde ocorreram situações que associou à falta de proteção de Deus. Falou por cerca de meia hora sobre como Deus a cobria de cuidados em diferentes circunstâncias na vida - na rua, era protegida de ladrões, e no casarão, era resguardada de 'assombrações e demônios'. No final da conversa, me aconselhou: "De coração, amiga, bom final de semana, que essa semana seja uma semana maravilhosa, tá? E muita pro- 
teção do Espírito Santo na vida de vocês! E quando sentir esse vulto? Tá reprendido em nome de Jesus! É só orar!” - e assim, seguiu ao trabalho, com balde e desinfetante nas mãos.

O diálogo com Dona Nazaré reflete uma das pautas que se tornou frequente durante minha pesquisa com os vigilantes que trabalham em casarões históricos, a saber, as narrativas sobre sentimentos de desproteção. A recorrência do assunto chamou minha atenção para certa ambiguidade na prática da vigilância: o profissional treinado para guardar, vigiar e proteger o patrimônio público, se sentia vulnerável diante de experiências difíceis de classificar, como o ouvir passos, sentir fragrâncias, ver espíritos, intuir presenças não materiais. Ou seja, em sua rotina de trabalho nos casarões do Centro Histórico, o vigilante percebia a manifestação de diversos seres e agências, como os ratos que faziam ruídos em uma biblioteca, o vento que batia uma porta ou balançava os vidros da janela, uma visagem que soprava em seus ouvidos. Estas manifestações se tornavam companhias em seus turnos. Foram esses relatos que me fizeram pensar que o encontro dos vigilantes com as casas (dado por um vínculo de trabalho) me permitia analisar uma composição de agências que acontecia nos prédios históricos e que interferia em sua própria constituição.

Os casarões localizados na área central da cidade, onde trabalham os vigilantes que conheci, são reconhecidos mundialmente por sua riqueza arquitetônica, que constitui marco da colonização portuguesa em São Luís. Desde 1997, a região recebeu o título de Patrimônio Mundial da Humanidade, concedido pela Organização das Nações Unidas para Educação, Ciência e Cultura (Unesco). A área de tombamento federal contempla 1.432 prédios e a área de tombamento estadual é formada por 4.400 casarões (Maranhão 1997). Eles são utilizados de diversas formas, além de residências, são ocupados por pousadas, museus, feiras, lojas, comércios, órgãos da administração pública, espaços culturais e restaurantes. Quando tombados, integraram uma lista de bens que, de interesse histórico, devem passar por alterações previstas e autorizadas pelos órgãos reguladores do patrimônio - que têm como foco principal a preservação dos imóveis. No intuito de evitar depredações, furtos ou qualquer tipo de lesão aos casarões, aqueles que abrigam serviços públicos possuem vigilância constante.

A pesquisa de campo da minha dissertação aconteceu em três prédios públicos, localizados no bairro da Praia Grande, a Faculdade de História da Universidade Estadual do Maranhão (Uema), o Arquivo Público do Estado do Maranhão e o Museu Histórico e Artístico do Maranhão (Gonçalves 2019). Meus interesses estavam voltados para narrativas e experiências dos vigilantes sobre as diversas entidades que povoavam as casas antigas e eram chamadas de termos diversos como 'assombrações, espíritos, visagens, fantasmas, entidades, demônios ou amiguinhos. Tomo emprestado, neste texto, o termo 'seres intangíveis' proposto por Blanes e Espírito Santo $(2014)^{1}$ pois, me ajuda a designar coletivamente essas nomenclaturas. Entretanto, quando remeto a situações específicas, prefiro utilizar as for-

1 Os autores ainda me ajudam a pensar essas presenças através dos seus efeitos na vida das pessoas, de forma a não as restringir ao âmbito da religião - buscando foco no sentir/ver/narrar os aspectos do invisível e as especificidades que tomam. 
mas de nomear usadas pelos meus interlocutores, uma vez que a maneira de se referir a essas presenças expressa uma variedade de modos de lidar com elas².

Neste texto, busco refletir sobre situações que remetem à vulnerabilidade das pessoas ou das casas em relação aos diferentes seres com os quais interagem. Na primeira seção, concentro a análise na trajetória de Joana e sua relação com o prédio do Arquivo Público, com intenção de mostrar o processo de 'se acostumar' ao trabalho no casarão. Esse processo, sugiro, nos permite pensar sobre uma inversão da lógica de proteção e risco. Na segunda seção, discorro sobre a desproteção das casas perante agências não humanas (cupins, ratos, baratas, ação do tempo/natureza) de forma a questionar a ideia de

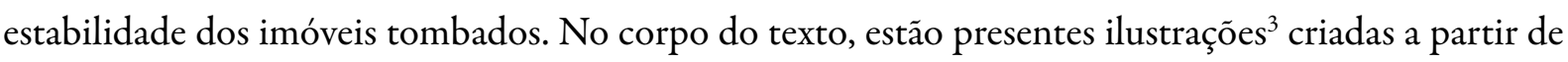
meus diários de campo. As descrições de eventos ou espaços acabaram por criar 'pequenos curtas' que fui registrando em escritos durante a pesquisa, como um caderno de campo visual (Camargo 2016).

\section{Joana e o Escapulário}

Em uma das conversas que tive com D30, ele sugeriu que eu fosse até o prédio do Arquivo Público do estado do Maranhão, pois disse que lá havia histórias sobre vozes de mulheres ecoando do sobrado. As tardes no prédio do Arquivo eram recheadas de conversas entre os funcionários e aqueles que passavam pelo local - vendedores de lanches dizendo os sabores do dia; a senhora que vendia remédios caseiros e xaropes com múltiplos benefícios; sorveteiros e guardadores de carro. No prédio, conheci Joana, a primeira vigilante mulher que tive contato. Uma mulher de estatura alta, cabelos escuros e lisos, escondidos pelo boné que compunha seu fardamento. Contei-lhe sobre os boatos que me levaram até o casarão e ela confirmou a indicação de $\mathrm{D} 30$, dizendo que não tinha dúvidas que as sensaçôes estranhas que sentia no trabalho eram espíritos de mulheres.

Localizado na Rua de Nazaré, o sobrado do Arquivo Público do estado do Maranhão (Apem) está em funcionamento desde 1978. No edifício, estão armazenados documentos de valor para a história do estado. Manuscritos, mapas, plantas de construções, jornais, imagens e documentos em versão única dos períodos coloniais, imperial e republicano compõem o acervo que é disponibilizado para pesquisadores e instâncias governamentais (São Luís 2008). No começo do século XX, no mesmo casarão, funcionava uma luxuosa casa de prostituição chamada "Pensão Chicó", lugar bastante frequentado pela elite da época e conhecido por batidas policiais.

\footnotetext{
2 Os termos mais utilizados pelos meus interlocutores foram visagens e espiritos. Porém, algumas pessoas utilizavam o pronome indefinido alguém - 'tem alguém aqui'; 'sinto alguém aqui, uma leitura que personalizava ou mesmo humanizava certo ser intangível. As menções a vultos e espíritos evidenciavam noções de tempo - vultos, eram tidos como um reflexo de uma presença passageira e repentina; enquanto o termo espíritos, era usado para se referir a um ser com estadia permanente em determinados compartimentos da casa. Os termos ainda podem ser mesclados no entendimento de que espíritos podem agir por meio de um vulto (quando passam, arrepiam ou se mostram visíveis em aparições).

3 As ilustrações foram criadas por minha amiga e também cientista social Éllen Cripf que teve acesso aos meus diários de campo. Intituladas 'As mulheres do Arquivo Público' (Figura 1.) e 'As companhias de um piano' (Figura 2.), fazem parte de um conjunto de ilustrações que estão presentes na minha dissertação (Gonçalves 2019). Os desenhos foram feitos a partir das minhas idas a campo, das narrativas de vigilantes, como um processo criativo de terceira mão. A Figura 2. 'As companhias de um piano', foi inspirada na descrição de um dos vigilantes do Museu Histórico e Artístico do Maranhão - na sala funcionava um pequeno teatro, comum nas casas do século XIX. A falta de uso do espaço causou uma infestação de cupins em um piano, que infelizmente foi perdido.
} 
Olhando de fora, o prédio possui dois pavimentos e um pequeno mirante. Nele há um subsolo com dois porões que dificilmente era frequentado por funcionários. Foi neste casarão que Joana viveu sua primeira experiência na carreira de vigilante, iniciada em 2008, logo após concluir o curso em uma empresa de segurança privada. Seu primeiro emprego com carteira de trabalho assinada foi contado com louvor, apesar de ter significado o começo de outros problemas - "Depois de uma semana eu comecei a sentir as coisas", lembrava. Joana iniciava seu turno às seis horas da tarde e permanecia durante toda a noite. Os primeiros dias foram marcados por certos estranhamentos, como os passos que a acompanhavam em sua ronda ao subir as escadas de madeira; os vultos que a rodeavam, arrepiando sua pele; o barulho das caixas pesadas com arquivos sendo arrastadas na biblioteca; as teclas que eram digitadas nos datilógrafos; e a máquina que, sozinha, cortava papéis. Em seus pensamentos, ela não tinha dúvidas que havia alguém no prédio junto dela e sobre isso, me disse: "Tinha dia que eu chegava aqui e que não dava vontade de entrar. A minha vontade era só voltar, era uma coisa tão... Eu me arrepiava dos pés à cabeça... Eu sentia uma matéria aqui”. Joana acreditava que as presenças que percebia estavam relacionadas aos acontecimentos do passado, principalmente às mulheres que moravam na Pensão Chicó: "São pessoas que não eram tementes a Deus. Não fizeram a passagem... Ficam penando na terra, o espírito não subiu", me contou.

Joana ainda confessou que sua adaptação a tais situações foi um processo lento e complicado. A sensação incômoda que as presenças intangíveis lhe causavam a fez procurar estratégias para que pudesse 'trabalhar em paz'. Após um mês na vigilância, ela dividiu seus sentimentos com sua madrinha, que lhe sugeriu buscar leituras que a ajudasse a driblar seus pensamentos ruins e a aproximassem de Deus. Desde então, ela fazia um 'ritual de entrada' em seus turnos: ao chegar ao prédio orava pedindo proteção de Deus, se acomodava em uma cadeira na varanda e lia livros de autoajuda. Os temas dos livros versavam sobre superação de pânicos e medos, pensamentos positivos e reflexões católicas. Somado a isso, levava um pequeno radinho, que colocava em alto volume, para não ouvir nenhum movimento que não fosse seu.

Sentada na varanda nas madrugadas, Joana observava nitidamente a rua e a Praça Benedito Leite - próximas ao prédio. $\mathrm{Na}$ Praça, avistou alguns vigilantes reunidos durante boa parte da noite. Certa vez conversou com eles e soube que eram vigilantes de casarões vizinhos. Depois desse dia, passou a acompanhá-los durante as noites, momentos nos quais contavam piadas, tomavam café, conversavam sobre as assombrações de seus respectivos prédios, convivendo nas madrugadas. 


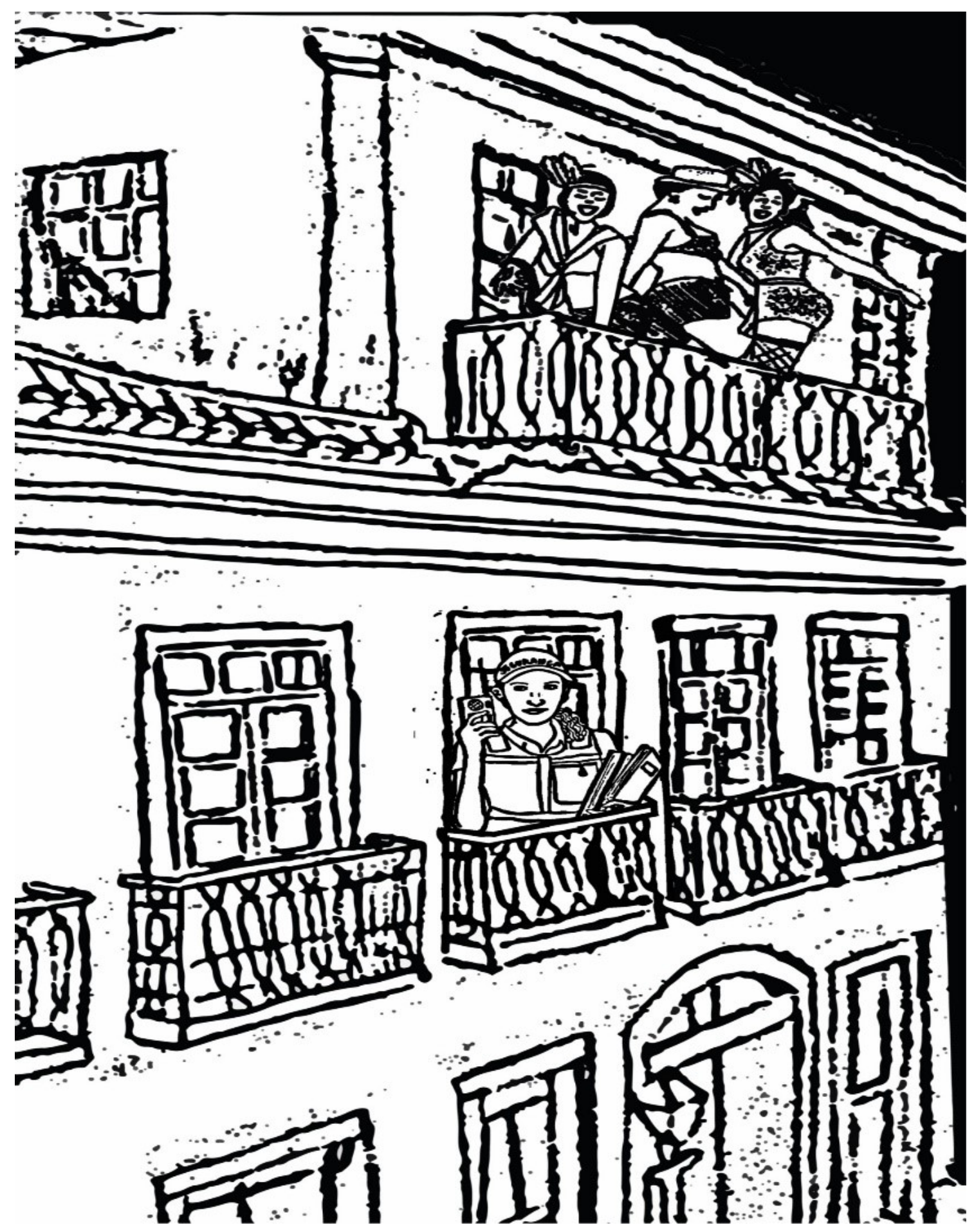

Figura 1. Ilustração 'As mulheres do Arquivo Público'

Mesmo buscando estratégias para que não sentisse as presenças que habitavam o casarão, Joana me contou que demorou cerca de dois anos para 'se acostumar' com elas. Os dias de paz no trabalho vieram quando foi presenteada por sua madrinha com um escapulário - um cordão que possui duas imagens de referência católica, normalmente a imagem de Jesus na frente e a imagem da Maria Imaculada Conceição na parte de trás. 
Joana - Eu senti medo até que minha madrinha comprou um escapulário pra mim.

$\mathrm{Eu}-\mathrm{O}$ que é um escapulário?

Joana - É um cordão que tem umas imagens que afasta entendeu? Aí tem duas imagens, uma imagem na frente e uma imagem atrás, aí eu pegava, quando eu chegava aqui eu colocava, parece assim que dava uma sensação de paz. Paz de espírito...

$\mathrm{Eu}-\mathrm{E}$ tu melhorou?

Joana - Melhorei... a sensação sabe... Aquela sensação melhorou bastante (Extrato de diário de campo, 30/11/2017).

O escapulário marcou o começo de turnos mais tranquilos para Joana. É comum a 'regra' entre os católicos de que não se deve comprar um escapulário para si mesmo - ele é um objeto para presentear alguém que esteja precisando de proteção e conforto espiritual. Desde que o recebeu, a vigilante passou a colocá-lo no pescoço toda vez que entrava para mais um plantão. Permaneceu por quatro anos vigiando durante a noite, até que aceitou uma oportunidade de transferência para trabalhar durante o dia, turno em que, segundo disse, as manifestações 'estranhas' eram menos evidentes.

Para entender o que Joana viveu é importante saber que as vivências de vigilantes nos casarões são facilmente diferenciadas da atividade de vigilância em outros lugares - os antigos sobrados são descritos como locais que carregam o passado em suas estruturas, na medida em que falam sobre a escravidão, sobre assassinatos e mortes conhecidas, sobre grandes festas e experiências religiosas. Todos esses elementos eram utilizados para falar sobre as manifestações sentidas nas casas. Joana, para conseguir trabalhar, teve que se acostumar com as manifestações no casarão, o que a levou à busca de diferentes estratégias e ao uso de diferentes objetos (o cordão, o rádio, os livros de autoajuda). Sua trajetória coloca em pauta noções de vulnerabilidade e de proteção e concentro minha análise sob dois pontos de vista: a busca por aparatos de proteção; e as inversões das lógicas de proteção ou risco.

Joana se sentia desamparada no casarão. Ela sentia 'uma matéria' que não lhe era agradável - eram vultos que passavam arrepiando sua pele ou objetos acionados sem humanos. Tudo isso somado a 'pensamentos ruins', lhe trazia uma atmosfera de desproteção espiritual. Naquele momento, percebeu que sua preparação profissional para lidar com ameaças (assaltos, furtos ou a depredação do prédio) não era eficaz para enfrentar a situação. Analiso as circunstâncias vividas por Joana como um evento crítico no qual, ao mesmo tempo em que o sujeito se encontra desprotegido, novas formas de subjetividade são estimuladas (Das 2016). Em um cenário no qual a arma de fogo não implicava em proteção, a vigilante buscou outros aparatos que serviriam para esse fim, por exemplo, as leituras de autoajuda, o rádio em alto volume e o escapulário. A despeito da diferença de contexto da análise de Veena Das (2016) - que trata da conjuntura das formas de violência na Partição da Índia, sugiro aproximar a experiência de Joana no casarão para pensar a agência dos sujeitos em condições de vulnerabilidade. Nesse sentido, a vigilante se deparou com um contexto que foi percebido como ameaçador, mas não podendo apenas negá-lo, buscou formas de amenizar angústias e sensações que ultrapassavam seu controle ou desejo. Isso não é exclusivo da trajetória de Joana, em outros relatos surge uma diversidade de estratégias utilizadas pelos seguranças no processo de se acostumar com os seres intangíveis. D30, o vigilante da Facul- 
dade de História, por exemplo, se referia a eles como 'amiguinhos', o que não implicava uma relação de proximidade ou afeto, antes indicava a busca de uma 'boa relação' que diminuísse incômodos.

Além das estratégias de proteção, penso que a trajetória de Joana fala ainda sobre uma inversão de lógica entre cuidado e risco. Os vigilantes vivenciam uma rotina de trabalho nos casarões que remete às suas próprias casas - se acomodam para cochilar, tomam banho, escovam os dentes, se distraem com a televisão, dispensam partes do fardamento para ficar à vontade. Porém, o casarão não necessariamente se configura como um lugar de conforto, uma vez que habitado por presenças e manifestações diversas. Nesse sentido, Joana, durante as madrugadas, não se protege dentro do casarão, mas na rua. Essa inversão de lógicas pode ser pensada através das considerações de DaMatta (1997), que sugere que enquanto as ruas são associadas a riscos, desordem, anonimato e movimentos desconhecidos, as casas seriam associadas à proteção, ao aconchego, à intimidade e à relação. Joana e seus colegas, dessa forma, questionam o enquadramento proposto pelo autor e indicam o contrário. Ao se reunirem na Praça durante a madrugada, desfrutam de um convívio prazeroso de conversas e brincadeiras, o que dissolve as noções de perigo. A imagem das ruas desertas à noite, como um cenário ameaçador, especialmente para as mulheres, ou da casa como espaço reservado e de proteção, é provocada na medida em que Joana se sente mais confortável na rua, 'exposta', acompanhada por homens, do que no âmbito da casa.

$O$ vigilante, profissional treinado para proteger alguma coisa, busca estratégias que não condizem com seus saberes institucionais, para que se sinta confortável ou protegido. Assim, no decorrer dos encontros com seres intangíveis, aciona novos recursos de conhecimento, guarda experiências sensoriais e desenvolve novas habilidades, tais como reconhecer e diferenciar barulhos de humanos, espíritos ou animais. Nesse sentido, o escapulário, aparece como o objeto que ocasionou a proteção que estava ausente e estabilizou a relação entre Joana, a casa e os seres intangíveis. Para ela, ele trouxe consigo a 'paz' que julgava precisar naquele momento em sua vida, cessando seus medos e desconfortos espirituais.

Essas situações de trabalho falam, portanto, do conhecimento e do reconhecimento da presença de seres humanos e não humanos nos casarões. Noções prévias sobre vida e morte, corpo e espírito, proteção e desproteção são repensadas, de forma que os sujeitos terminam por desenvolver habilidades, atenções e entendimentos sobre o que constitui o processo de coabitar. Podemos afirmar com Ingold (2015:38), que "Ao longo desses caminhos, vidas são vividas, habilidades desenvolvidas, observações feitas e entendimentos crescem". Logo, os vigilantes compreendem que dividem o espaço dos casarões com vultos e espíritos que insistem em mostrar suas presenças e que interditam ou marcam espaços como seus. Além deles, outras manifestações acontecem nos prédios, elas remetem a muitos outros seres, que também falam sobre a história dos casarões, sua vulnerabilidade e os efeitos da passagem do tempo.

\section{Cupins, ratos, baratas e reformas}

Seu Daniel, companheiro de turno de Joana, trabalhava no casarão do Arquivo Público desde 1992. Acostumado a 'vigiar da rua', me contou que as infestações de ratos e baratas nos anos noventa aconteciam durante as madrugadas. Avistou muitas 'gangues' de animais saírem das galerias de saneamento entreabertas. As baratas, foram descritas como pragas festeiras: "E as baratas daqui gostam de uma cachaça! Tu 
já deu cachaça pra elas?” - me questionou, com bastante bom humor, ao sugerir que elas tinham apreço pelos dias de grande movimento festivo no Centro Histórico. Os ratos, além de serem roedores exímios de objetos, alimentos e diversas texturas, eram famosos pelo tamanho fora do comum.

Durante seus turnos, Seu Daniel convivia com uma mistura de entidades - a mulher de branco (um espírito que aparecia na rua), ratos, baratas e cupins. Animais, participavam do cotidiano do bairro da Praia Grande - nas ruas de paralelepípedos se podia ver famílias de pombos, os gatos costumavam estar nas proximidades dos restaurantes ou feiras, os ratos saíam, à noite, dos bueiros. Por vezes, Seu Daniel acordava de um cochilo com o barulho feito por eles, que não raro, eram confundidos com seres intangíveis, uma vez que nem sempre era possível saber quem ou o que produzia barulho ou se aproximava das pessoas. Os cupins eram descritos, pelos vigilantes, como seres pequenos e habilidosos, pois em uma só noite poderiam construir casas em madeiras e papéis. As baratas, eram os animais tidos como menos nocivos, pois, segundo Seu Daniel, bastava lhes dar algumas doses de cachaça para que fossem embora.

Não apenas os animais agiam sobre os objetos guardados ou a própria estrutura do prédio. Havia ainda 'elementos da natureza' que influíam sobre a vulnerabilidade das construções. Em período chuvoso, cerca de seis meses ininterruptos na cidade, as goteiras começavam a surgir. Quando estava em campo, avistei baldes sendo alocados na entrada do prédio do Arquivo, para conter as gotas d'água. Manchas e mofo faziam desenhos pelas paredes, até que elas fossem novamente pintadas. A natureza agia ainda sobre o que os casarões deveriam guardar e proteger: os documentos e papéis arquivados estavam sempre sob risco, poderiam ser molhados, roídos por ratos ou comidos por cupins, perdidos ou amassados.

Nos prédios históricos, o vigilante era um dos porta-vozes que notificava à administração do órgão sobre as deteriorações feitas por animais ou pela ação das chuvas, comunicando infiltrações, goteiras, objetos roídos, casas de cupins ou rachaduras aos responsáveis pela manutenção do espaço. Nesse sentido, ele não era apenas um profissional que vigiava a ação dos humanos sobre o patrimônio, ele parecia acompanhar um conjunto de agências que interagiam com o casarão.

Uma das formas de conter a agência e a presença dos diversos seres de um casarão, é realizar reformas. As reformas no perímetro do Centro Histórico têm como responsáveis principais o Instituto de Patrimônio Histórico e Artístico Nacional (Iphan), Governo do Estado do Maranhão e a Prefeitura de São Luís (os dois últimos através de secretarias ou órgãos). O edifício do Arquivo Público sofreu duas intervenções desde que foi inaugurado em 1987: uma reforma interna para a adaptação do Laboratório de Conservação e Restauração de Papéis; e uma intervenção para climatização e informatização em 1998. Seu Daniel acrescentou que, fora as reformas mais expressivas, em épocas de chuva são realizados reparos para acabar com as infiltrações, que podem ameaçar os papéis importantes que estão guardados no local. Ele me contou que a última reforma, em 1998, trouxe várias transformações ao casarão: portas e janelas foram substituídas, a fiação da eletricidade subterrânea renovada, os compartimentos internos foram completamente dedetizados, lâmpadas novas foram instaladas, as infiltrações reparadas e o sistema de esgoto da rua passou por um procedimento de limpeza.

As reformas são, elas mesmas, momento delicado no que tange à conservação do casarão e dos bens que guarda. Conhecidas pelo longo tempo de espera para que fiquem concluídas no Maranhão, 
$e^{e l a s}{ }^{4}$ promovem o encontro de forças não favoráveis a preservação das casas e bens. Na parte interna dos prédios, as reformas tiram objetos do seu lugar, os aglomeram em pequenos compartimentos inadequados; colocam texturas em contato, podendo deteriorar itens; inutilizam sistemas de refrigeração fazendo a temperatura abafada favorecer a proliferação de cupins ou outras pragas. Na parte externa, as chuvas fortes e ventos podem derrubar as estruturas de madeira que seguram os casarões, as plantas crescem e espalham suas raízes pelo alicerce causando rachaduras. Não raro, reformas longas podem levar ao desabamento de casarões.

As reformas podem, então, ser um risco. Quando acontecem no tempo estimado, amenizam as infestações de ratos, baratas e cupins. Um efeito inesperado, entretanto, ficou evidente na fala de Seu Daniel: elas podem levar consigo a presença de espíritos. Outros vigilantes mencionaram coisas semelhantes, dizendo que, por exemplo, a troca de lâmpadas (que permitia maior claridade aos ambientes), a substituição de portas e fechaduras, eram 'melhorias' que repeliam as presenças intangíveis. Da forma como me contaram, parecia que as reformas permitiam identificar espíritos como presenças históricas relacionadas intrinsecamente aos casaróes, que mostravam resistência a certas transformações. Enquanto as reformas, para os órgãos de manutenção do Centro Histórico, eram condição de preservação dos imóveis tais como já foram 'originalmente', para Seu Daniel, ao serem feitas, elas modernizavam os espaços, podendo afastar o passado.

Sugiro, portanto, que os casarões engajam diferentes entidades (Ingold 2012) - espíritos, ratos, cupins, baratas, ações do tempo ou natureza e humanos - que juntas habitam e interferem em sua formação. Tsing (2015) propõe, a partir da análise dos cogumelos, atentarmos às interações multiespécies, na medida que elas questionam a superioridade humana. Tanto a autora como Ingold, lembram que há um fluxo de movimento que não precisa da agência humana para acontecer. Como mero participante de relações multiespécies, o vigilante vivencia situações e preocupações que extrapolam sua atividade de guardar o patrimônio. Ele vigia a casa e os engajamentos que nela se encontram: observa as escadas de madeira, portas ou janelas, que podem ser roídas por cupins e ser facilmente inutilizadas; os ventos que podem afastar telhas; as chuvas que podem causar goteiras; os ratos que podem destruir bens incalculáveis e também os espíritos.

\footnotetext{
4 Por mais que as intervenções tenham estimativas de tempo/custo para execução, não é incomum que sejam iniciadas e interrompidas no processo. A título de exemplo, o Museu Histórico e Artístico do Maranhão passou dez anos em reforma - algumas peças do acervo foram deterioradas e documentos institucionais foram perdidos. Para além de um casarão em desuso que está sujeito à ação do tempo/ natureza e animais, existem os prédios em uso formal e informal ou que necessitam de intervenção urgente, vulneráveis da mesma forma. Em março de 2019, uma tempestade derrubou uma moradia localizada na Rua Jacinto Maia, no Centro Histórico de São Luís. Reportagem da Rede Mirante de televisão, disponível em: http://g1.globo.com/ma/maranhao/videos/v/apos-forte-chuva-casarao-desaba-em-sao-luis/7483073/
} 


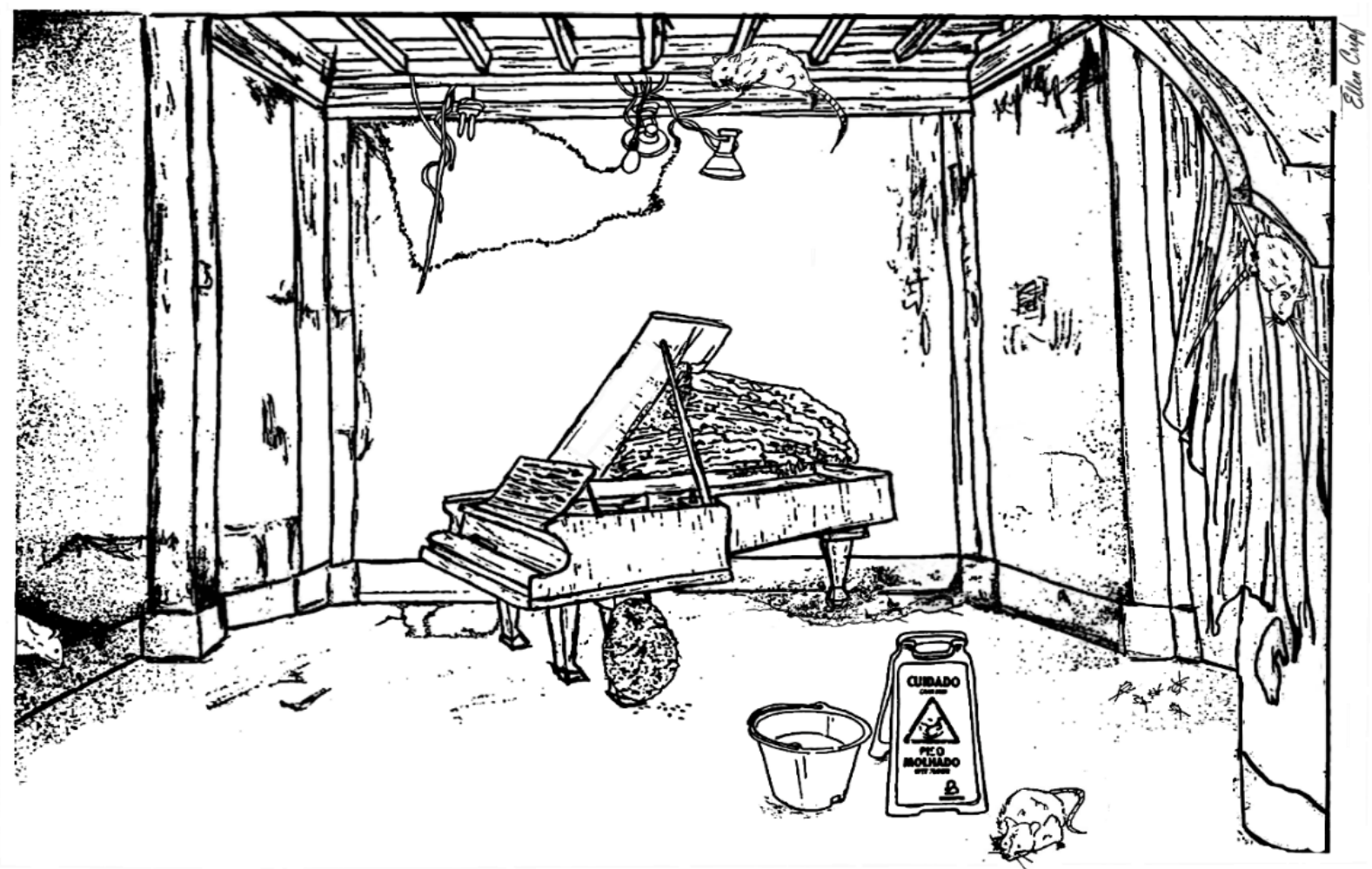

Figura 2. Ilustração 'As companhias de um piano'.

\section{Considerações Finais}

A intenção desse artigo foi trazer à tona as formas de vulnerabilidade às quais pessoas e casas estão sujeitas no Centro Histórico de São Luís. Acompanhando um grupo de vigilantes de três casaróes tive a oportunidade de conhecer um contexto em que seres não humanos fazem parte da rotina de trabalho e levam os profissionais a observarem suas próprias vidas de outra forma. Por intermédio de um vínculo empregatício, os vigilantes terminam por realizar o exercício de repensar os sentidos de proteção que estão contemplados em suas técnicas de guardar e vigiar. Assim, a descoberta de que estão vulneráveis provoca os sujeitos a buscar novos aparatos - conversas, orações, leituras, objetos, que se tornam talismãs e instrumentos de enfrentamento. A relação que Joana desenvolveu com o escapulário marca o momento em que encontrou conforto no trabalho, foi o que permitiu se acostumar com o casarão (se situar nos espaços, construir familiaridade); com os seres intangíveis (quando desenvolveu um conjunto de práticas para lidar com as presenças); e com a dinâmica do seu emprego de vigilante.

Da mesma forma, ao enfrentarem seus estranhamentos nos casarões, os vigilantes adquiriam novas dimensões de conhecimento - dispositivos de reconhecimento ou distinção entre presenças humanas ou não humanas e o desenvolvimento de habilidades sensoriais (ouvir/sentir/ver). Como distinguir um som produzido por um humano ou espírito? Como reconhecer a ação de um humano ou um rato? Percebemos essas estratégias de reconhecimento e enfrentamento em vários momentos: 
Dona Nazaré me ensinando como agir caso eu sentisse um vulto; Joana em busca de estratégias para sentir conforto espiritual; Seu Daniel observando as infestações de animais e pragas.

Nas histórias que pude acessar, o casarão é como um ponto de encontro que reúne diferentes engajamentos que perpassam a trajetória de um vigilante, ele é a morada de entidades diversas. Mas, além disso, ele também é vulnerável, instável e sujeito às agências que o habitam. Pensar a vulnerabilidade dos casarões evidencia os efeitos das ações de animais, do tempo e da natureza no processo de deterioração das características coloniais das casas, nos desabamentos, acidentes, isolamentos e reformas.

\section{Gabriela Lages Gonçalves é mestra pelo Programa de Pós-Graduação em Ciências Sociais da Universidade Federal do Maranhão (UFAM).}

\section{REFERÊNCIAS BIBLIOGRÁFICAS}

BLANES, Ruy. ESPÍRITO SANTO, Diana. 2014. "Introduction: on the agency of intangible”. In: BLANES, R.; ESPÍRITO SANTO, D. (orgs.). The Social Life of Spirits. Chicago and London: The University of Chicago Press.

CAMARGO, Fernando Monteiro.2016. "Desenhando nas margens. Diário de campo visual de uma experiência etnográfica”. Cadernos de Arte e Antropologia, 5(2): 103-107.

DAMATTA, Roberto. 1997. A casa e a rua: espaço, cidadania, mulher e morte no Brasil. 5. ed. Rio de Janeiro: Rocco.

DAS, Veena. 2016. “O ato de testemunhar: violência, gênero e subjetividade”. Cadernos Pagu, 37: $9-41$.

GONÇALVES, Gabriela Lages. 2019. Quem vigia o casarão? Uma análise sobre a convivência entre vigilantes e seres intangiveis no Centro Histórico de São Luís. Dissertação (mestrado). Programa de Pós-Graduação em Ciências Sociais. Universidade Federal do Maranhão, São Luís.

INGOLD, Tim. 2012. “Trazendo as coisas de volta à vida: emaranhados criativos num mundo de materiais". Horizontes Antropológicos, 18(37): 25-44.

. 2015. "A antropologia ganha vida". In: Ingold, T. Estar vivo: ensaios sobre movimento, conhecimento e descrição. Petrópolis: Vozes.

MARANHÃO. 1997. São Luís: Secretaria do Estado da Cultura do Maranhão, 1997. Dossiê: Proposta de Inclusão do Centro Histórico de São Luís na Lista do Patrimônio Mundial da UNESCO. SÃO LUÍS. 2008. Fundação Municipal de Patrimônio Histórico (FUMPH). Instituto do Patrimônio Histórico e Artístico Nacional (IPHAN). São Luis: Ilha do Maranhão e Alcântara: Guia de Arquitetura e Paisagem. São Luís: Junta de Andalucia.

TSING, Anna. 2015. “Margens Indomáveis: cogumelos como espécies companheiras”.

Ilba Revista de Antropologia, 17(1): 177-201. 
ENTRE VISAGENS E CASARÕES: CONSIDERAÇÕES SOBRE FORMAS DE VULNERABILIDADE A PARTIR dos VigiLANTES DO CENTRO HiSTÓRICO DE SÃo LUÍS

Resumo: Este artigo parte da minha pesquisa de mestrado com vigilantes de prédios públicos em São Luís, localizados no perímetro histórico da cidade. Visagens, espiritos ou assombrações, acompanham cotidianamente o trabalho de vigilantes nos casarões e são identificados por diversas formas de manifestação - sons, cheiros, toques ou aparições. Neste trabalho, proponho uma análise da relação de convivência entre pessoas, casas e seres intangíveis, tendo como ponto de partida perspectivas de proteção e desproteção. Dessa forma, organizo o texto em dois momentos: o primeiro, dedica-se a reunir noções de proteção/desproteção a partir da trajetória de Joana, uma das vigilantes do casarão; o segundo, busca apresentar como intervenções não humanas (animais, ação do tempo/natureza) podem impactar os casarões, tornando-os possivelmente vulneráveis. A partir disso, busco apresentar como noções de proteção/risco podem ter seus sentidos transformados, e podem revelar engajamentos entre diferentes agências - como humanos, natureza, tempo ou seres intangíveis.

Palavras-chave: Casarões; Espíritos; Vulnerabilidade.

\section{BETWEEN GHOSTS AND BUILDINGS: CONSIDERATIONS ON FORMS OF VULNERA- BILITY EXPERIENCED BY SECURITY GUARDS OF SÃO LUIS, MARANHÃO, BRAZIL}

Abstract: This article results from my master's degree research among security guards of public buildings located in the historical area of São Luís, Maranhão, Brazil. Visions, spirits or hauntings have often followed the security guards' work in these buildings, which are perceived in many ways - noises, smells, touches or apparitions. In this paper, I propose to analyze the relationship between people, houses and intangible beings, taking perspectives of protection and lack of protection as a starting point. In order to do so, this text is divided in two sections: the first gathers notions of protection/vulnerability from the trajectory of Joana, one of the security guards; and the second seeks to present how non-human interventions (animals, time or nature) can impact the buildings, making them possibly vulnerable. Considering all this, I present how notions of risk or protection can have their meanings transformed and may reveal engagements among different agencies - such as humans, nature, time, or intangible beings.

Keywords: Houses; Spirits; Vulnerability.

RECEBIDO: $18 / 02 / 2019$

APROVADO: $28 / 06 / 2019$ 